\title{
AN INFERRED CHIASMA MAP OF DROSOPHILA MELANOGASTER
}

\author{
N. E. MORTON, D. C. RAO and S. YEE \\ Population Genetics Laboratory, University of Howaii, Honolulu, 96822
}

Received 13.v.76

\section{Summary}

The chiasma map of $D$. melanogaster is inferred from the genetic map, giving correspondences between physical and genetic locations. Crossing-over is reduced near the centromere and telomeres. If chiasmata occur preferentially near the telomere they must be distal to genetic loci. A precept of Bridges and Morgan is discussed, which Drosophila genetics neglected but chromosome mapping in other organisms should follow.

\section{INTRODUCTION}

A chiasma map gives the distribution of observed or inferred chiasmata in relation to cytological markers. On the assumption of a precise correspondence between sites of chiasmata and crossing-over the chiasma map is a genetic map which integrates cytological and genetic observations. Drosophila is unusual in presenting great difficulty for cytological observation on meiosis but a wealth of genetic information from which the distribution of chiasmata can be inferred, free of uncertainty about preanaphase terminalisation and loss. This distribution for oogenesis may be relevant to other organisms like man where meiotic observations (on spermatogenesis) can be made more easily than in Drosophila but not so precisely that movement and loss can be neglected with assurance, and where genetic data are insufficient to infer the distribution of chiasmata (Morton et al., 1976).

\section{ThEORY}

We assume that the distribution of crossing-over on a chromosome arm is compound,

$$
f(x)=A \beta_{1}(x)+(1-A) \beta_{2}(x) \quad(0 \leqq A \leqq 1)
$$

where $\beta_{i}(x)$ is a simple beta density function

$$
\begin{aligned}
& \beta_{1}(x)=\frac{(C+D+1) !}{C ! D !} x^{\mathrm{C}}(1-x)^{D} \quad(C, D>-1) \\
& \beta_{2}(x)=\frac{(2 E+F+1) !}{E !(E+F) !} x^{E}(1-x)^{E+F} \quad(E>-1, F>-1-E) .
\end{aligned}
$$

Capital letters denote parameters and $0 \leqq x<1$ is the relative distance of a point on the physical chromosome arm measured from the centromere.

PGL paper no. 149. This work was supported by Grant GM 17173 from the U.S. National Institutes of Health.

$37 / 3-G$ 
This distribution is extremely flexible and was chosen to give a good fit to chromosome arms of less than $100 \mathrm{cmo}$, which have an average of 2 chiasmata. If distance is measured in salivary bands, then the value of $x_{j}$ corresponding to the $c_{j}$ th band from the left telomere is

$$
x_{j}= \begin{cases}1-c_{j} / C_{l} & \text { for the left arm } \\ \left(c_{j}-C_{l}\right) / C_{r} & \text { for the right arm }\end{cases}
$$

where $C_{l}, C_{r}$ are the number of bands in the left and right arms, respectively (Bridges, 1942). Then the expected genetic locus corresponding to $x_{j}$ is

$$
z_{j}= \begin{cases}L_{l}\left[1-\int_{0}^{x_{j}} f(x) d x\right] & \text { for the left arm } \\ L_{l}+L_{r} \int_{0}^{x_{j}} f(x) d x & \text { for the right arm }\end{cases}
$$

where $L_{l}$ and $L_{r}$ are the genetic lengths of the left and right arms respectively.

Arm length is only approximate. An independent estimate is

$$
L=\frac{w_{t}}{\int_{0}^{x} f(x) d x}
$$

where $t$ is the terminal locus on the arm and $w_{t}$ is its location on the genetic map.

We used the cytogenetic maps of Lindsley and Grell (1968), assigning approximate locations to genetic markers known to lie in an interval. For example, the dor locus which has a step function that extends from band $1 \mathrm{Fl}$ to band $2 \mathrm{~A} 2$ was assigned to band $1 \mathrm{~F} 3$ for our calculations. Where an interval on the genetic map corresponds to a cytogenetic step function, we placed the terminal loci at the extremes and ignored intermediate loci. For example, 21 loci from $p l$ to $s d$ have the step function 13B2 to F17: we placed $p l$ in 13B2, $s d$ in 13F17, and omitted the other 19 loci.

Parameters of the beta distribution are estimated by minimising the discrepancy between observed and expected map segments. By analogy with a likelihood ratio the function to be minimised is taken to be

$$
Q=\sum_{j=1}^{N} \Delta w_{j} \ln \left(\Delta w_{j} / \Delta z_{j}\right)
$$

where $\Delta w_{j}=w_{j}-w_{j-1}$, an observed segment of the genetic map (map distance between loci $j$ and $j-1$ ), and $\Delta z_{j}=z_{j}-z_{j-1}$, its expected value. This criterion gives appropriate weight to small and large values of $\Delta w_{j}$, unlike the usual quadratic form.

\section{REsults}

Estimates of genetic arm lengths are in extremely good agreement with conventional values (tables 1 and 2). There is a highly significant deficiency of crossing-over near the centromere and telomeres $\left(\chi_{6}^{2}=16 \cdot 7\right)$ and the distribution is asymmetrical $\left(\chi_{6}^{2}=101 \cdot 0\right)$. Fitting only one beta function 
TABLE 1

Parameters of chromosome arms (Bridges, 1942)

\begin{tabular}{|c|c|c|c|c|c|c|c|}
\hline & \multicolumn{6}{|c|}{ Arm } & \multirow[b]{2}{*}{ Total } \\
\hline & $\mathrm{x}$ & $2 \mathrm{~L}$ & $2 \mathbf{R}$ & $3 \mathrm{~L}$ & $3 \mathbf{R}$ & 4 & \\
\hline Number of salivary bands & 1011 & 803 & 1136 & 884 & 1178 & 137 & 5149 \\
\hline $\begin{array}{l}\text { Number of loci used for } \\
\text { map }\end{array}$ & 52 & 18 & 23 & 11 & 18 & 4 & 126 \\
\hline Physical length in $\mu$ & 414 & 370 & 446 & 424 & 519 & 46 & 2219 \\
\hline Genetic length, $\mathrm{L}$, & $66 \cdot 0$ & $55 \cdot 0$ & $53 \cdot 0$ & $47 \cdot 8$ & $58 \cdot 5$ & $3 \cdot 0$ & $283 \cdot 3$ \\
\hline
\end{tabular}

$(A=0)$ is inadequate $\left(\chi_{16}^{2}=37 \cdot 6\right)$, implicating at least a second beta function. Mather (1936) made this observation and attributed it to chiasma localisation, with interstitial regions of interference. Alternatively, as discussed below, the reluctance of Drosophila geneticists to revise the genetic map may have created spurious saltations.

The maxima are estimated to be at $C /(C+D)$ and $E /(2 E+F)$, the modes of the beta functions (table 2). If chiasmata occur preferentially near the telomere, they must be distal to genetic loci (fig. 1). This is strongly suggested by chromosome 4 , which has virtually no crossing-over in the distal regions of the physical map. A terminal chiasma might be postulated to

TABle 2

Estimates and tests of hypotheses

\begin{tabular}{|c|c|c|c|c|c|c|c|c|}
\hline Hypothesis & & $\mathrm{X}$ & $2 \mathrm{~L}$ & $2 \mathrm{R}$ & $3 \mathrm{~L}$ & $3 \mathbf{R}$ & 4 & Total \\
\hline \multicolumn{9}{|l|}{ Uniform distribution } \\
\hline Symmetry $(\mathrm{A}=\mathrm{F}=0)$ & $Q$ & $0 \cdot 148$ & $0 \cdot 127$ & 0.084 & 0.183 & $0 \cdot 169$ & 0.013 & $0 \cdot 72$ \\
\hline \multirow[t]{3}{*}{ Homogeneity $(\mathrm{A}=0)$} & $Q$ & $0 \cdot 147$ & 0.085 & 0.051 & 0.072 & $0 \cdot 055$ & $0 \cdot 005$ & 0.41 \\
\hline & $\widetilde{E}$ & $0 \cdot 394$ & $1 \cdot 043$ & 0.699 & $1 \cdot 874$ & $1 \cdot 161$ & $6 \cdot 334$ & - \\
\hline & $F$ & -0.054 & $-0 \cdot 680$ & -0.558 & $-1 \cdot 458$ & -1.080 & $-2 \cdot 901$ & 一 \\
\hline \multirow[t]{3}{*}{ Heterogeneity } & $Q$ & $0 \cdot 123$ & 0.068 & $0 \cdot 040$ & $0 \cdot 026$ & $0 \cdot 043$ & 0.000 & $0 \cdot 30$ \\
\hline & $\widetilde{\text { d.f. }}$ & 47 & 13 & 18 & 6 & 13 & $1 *$ & 98 \\
\hline & $A$ & 0.876 & $0 \cdot 800$ & $0 \cdot 803$ & $0 \cdot 644$ & $0 \cdot 849$ & $0 \cdot 828$ & - \\
\hline$C /(C+D)$ & & $0 \cdot 403$ & 0.853 & $0 \cdot 815$ & 0.575 & $1 \cdot 000$ & $0 \cdot 655$ & - \\
\hline \multirow[t]{2}{*}{$E /(2 E+F)$} & & $0 \cdot 861$ & $0 \cdot 327$ & $0 \cdot 157$ & 0.920 & $0 \cdot 403$ & 一 & - \\
\hline & $L$ & $66 \cdot 1$ & $55 \cdot 0$ & $53 \cdot 1$ & $47 \cdot 8$ & $58 \cdot 5$ & $3 \cdot 1$ & $283 \cdot 6$ \\
\hline
\end{tabular}

* Assuming $C=D=0$.

Testing for uniform distribution: $\chi_{6}^{2}=(0 \cdot 775-0 \cdot 724) /(0 \cdot 300 / 98)=16 \cdot 7$

Testing for symmetric distribution: $\chi_{6}^{2}=(0 \cdot 724-0 \cdot 415) /(0 \cdot 300 / 98)=101 \cdot 0$.

Testing for $A=0: \chi_{16}^{2}=(0 \cdot 415-0 \cdot 300) /(0 \cdot 300 / 98)=37 \cdot 6$.

account for regular disjunction of this chromosome, whose genetic length is only $0.2 \mathrm{cmo}$ in diploids and $3.1 \mathrm{cmo}$ in diplo- 4 triploids. Suppression of distal crossing-over would then be evidence that terminal chiasmata show interference with medial chiasmata.

\section{Discussron}

Both physical and genetic locations are subject to errors. Most physical assignments are not to a single band, but to an interval covered by a deletion. Genetic locations are computed as sums of small distances, each with some 
error of estimation, perhaps biased due to differential viability and incomplete penetrance, and only in the limit strictly additive. Since an approximate relation between the physical and genetic maps may be of interest, the genetic location for the rightmost salivary band in each conventional region has been estimated (table 3 ) by integrating the beta distribution up to that band, using formula 26.5.4 of Abramowitz and Stegun (1965).

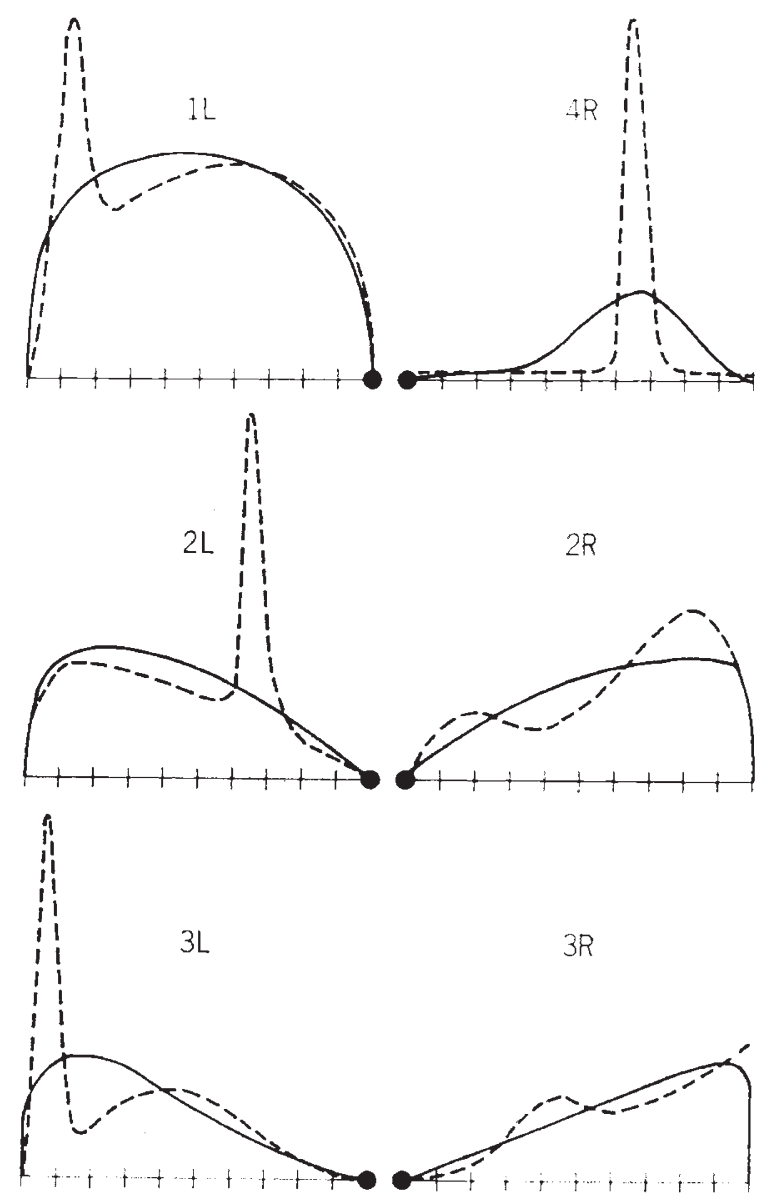

FIG. 1.-Chiasma distribution inferred in D. melanogaster from physical locations of genetic loci. - centromere; —-, single beta distribution; ----, double beta distribution.

The correspondence of the two maps is illustrated in table 4. Band $y$ lying in an interval between bands $x$ and $z$, with assigned map locations $w_{x}$ and $w_{z}$, is estimated to have location.

and conversely

$$
w_{y}=w_{x}+(y-x)\left(w_{z}-w_{x}\right) /(z-x)
$$

$$
y=x+\left(w_{y}-w_{x}\right)(z-x) /\left(w_{z}-w_{x}\right) .
$$

In the worst example the assigned and estimated map locations differ by 2.3 cmo or 38 bands (table 4 ). However, most estimates are more reliable, 
TABle 3

A chiasma map of $\mathrm{D}$. melanogaster

Chromosome 1

\begin{tabular}{ccc}
\hline Band & $\begin{array}{c}\text { Physical } \\
\text { locus } c\end{array}$ & $\begin{array}{c}\text { Genetic } \\
\text { locus } w\end{array}$ \\
1F4 & 40 & $0 \cdot 5$ \\
2F6 & 87 & $1 \cdot 9$ \\
3F9 & 136 & $6 \cdot 7$ \\
4F 14 & 188 & $12 \cdot 9$ \\
5F6 & 244 & $16 \cdot 8$ \\
6F11 & 290 & $19 \cdot 5$ \\
7F 10 & 358 & $23 \cdot 8$ \\
8F 10 & 422 & $28 \cdot 1$ \\
9F13 & 475 & $31 \cdot 9$ \\
10F11 & 538 & $36 \cdot 4$ \\
11F8 & 604 & $41 \cdot 3$ \\
12F7 & 654 & $45 \cdot 1$ \\
13F18 & 724 & $50 \cdot 2$ \\
14F6 & 773 & $53 \cdot 6$ \\
15F9 & 818 & $56 \cdot 7$ \\
16F8 & 867 & $59 \cdot 8$ \\
17F3 & 910 & $62 \cdot 2$ \\
18F5 & 960 & $64 \cdot 6$ \\
19F6 & 992 & $65 \cdot 7$ \\
20F4 & 1011 & $66 \cdot 1$ \\
& &
\end{tabular}

Chromosome 3L

$\begin{array}{lcc}\text { Band } & \begin{array}{c}\text { Physical } \\ \text { locus } c\end{array} & \begin{array}{c}\text { Genetic } \\ \text { locus } w\end{array} \\ 61 \mathrm{~F} 8 & 33 & 0 \cdot 1 \\ 62 \mathrm{~F} 6 & 83 & 11 \cdot 3 \\ 63 \mathrm{~F} 7 & 129 & 17 \cdot 9 \\ 64 \mathrm{~F} 5 & 198 & 20 \cdot 4 \\ 65 \mathrm{~F} 11 & 252 & 23 \cdot 1 \\ 66 \mathrm{~F} 6 & 327 & 28 \cdot 0 \\ 67 \mathrm{~F} 4 & 384 & 32 \cdot 0 \\ 68 \mathrm{~F} 8 & 430 & 35 \cdot 2 \\ 69 \mathrm{~F} 7 & 472 & 38 \cdot 0 \\ 70 \mathrm{~F} 7 & 524 & 41 \cdot 1 \\ 71 \mathrm{~F} 5 & 554 & 42 \cdot 6 \\ 72 \mathrm{~F} 4 & 585 & 44 \cdot 0 \\ 73 \mathrm{~F} 4 & 625 & 45 \cdot 4 \\ 74 \mathrm{~F} 4 & 654 & 46 \cdot 2 \\ 75 \mathrm{~F} 11 & 709 & 47 \cdot 2 \\ 76 \mathrm{~F} 3 & 748 & 47 \cdot 5 \\ 77 \mathrm{~F} 5 & 786 & 47 \cdot 7 \\ 78 \mathrm{~F} 4 & 824 & 47 \cdot 8 \\ 79 \mathrm{~F} 6 & 855 & 47 \cdot 8 \\ 80 \mathrm{~F} 9 & 884 & 47 \cdot 8\end{array}$

Chromosome 2L

\begin{tabular}{lcc}
\hline & $\begin{array}{c}\text { Physical } \\
\text { Band }\end{array}$ & $\begin{array}{c}\text { Genetic } \\
\text { locus } w\end{array}$ \\
21F3 & 31 & $2 \cdot 1$ \\
22F4 & 65 & $4 \cdot 8$ \\
23F6 & 103 & $8 \cdot 0$ \\
24F8 & 141 & $11 \cdot 2$ \\
25F5 & 187 & $15 \cdot 0$ \\
26F7 & 233 & $18 \cdot 8$ \\
27F7 & 270 & $21 \cdot 7$ \\
28F5 & 315 & $25 \cdot 0$ \\
29F8 & 350 & $27 \cdot 5$ \\
30F6 & 394 & $30 \cdot 4$ \\
31F5 & 432 & $32 \cdot 7$ \\
32F4 & 460 & $34 \cdot 2$ \\
33F5 & 508 & $37 \cdot 0$ \\
34F5 & 557 & $48 \cdot 2$ \\
35F12 & 601 & $51 \cdot 5$ \\
36F11 & 654 & $53 \cdot 1$ \\
37F6 & 698 & $54 \cdot 0$ \\
38F6 & 743 & $54 \cdot 7$ \\
39F3 & 773 & $54 \cdot 9$ \\
40F6 & 803 & $55 \cdot 0$
\end{tabular}

Chromosome 3R

$\begin{array}{ccc}\text { Band } & \begin{array}{c}\text { Physical } \\ \text { locus } c\end{array} & \begin{array}{c}\text { Physical } \\ \text { locus } w\end{array} \\ 81 \mathrm{~F} 6 & 890 & 47 \cdot 8 \\ 82 \mathrm{~F} 11 & 932 & 47 \cdot 8 \\ 83 \mathrm{~F} 4 & 976 & 47 \cdot 9 \\ 84 \mathrm{~F} 16 & 1039 & 48 \cdot 2 \\ 85 \mathrm{~F} 16 & 1130 & 49 \cdot 0 \\ 86 \mathrm{~F} 11 & 1200 & 50 \cdot 3 \\ 87 \mathrm{~F} 15 & 1275 & 52 \cdot 9 \\ 88 \mathrm{~F} 9 & 1339 & 56 \cdot 3 \\ 89 \mathrm{~F} 4 & 1407 & 60 \cdot 5 \\ 90 \mathrm{~F} 11 & 1456 & 63 \cdot 5 \\ 91 \mathrm{~F} 13 & 1503 & 66 \cdot 1 \\ 92 \mathrm{~F} 13 & 1571 & 69 \cdot 7 \\ 93 \mathrm{~F} 14 & 1633 & 73 \cdot 0 \\ 94 \mathrm{~F} 6 & 1701 & 76 \cdot 9 \\ 95 \mathrm{~F} 15 & 1768 & 81 \cdot 2 \\ 96 \mathrm{~F} 14 & 1855 & 87 \cdot 5 \\ 97 \mathrm{~F} 11 & 1917 & 92 \cdot 6 \\ 98 \mathrm{~F} 14 & 1972 & 97 \cdot 4 \\ 99 \mathrm{~F} 11 & 2027 & 102 \cdot 7 \\ 100 \mathrm{~F} 5 & 2062 & 106 \cdot 3\end{array}$

Chromosome 2R

\begin{tabular}{|c|c|c|}
\hline Band & $\begin{array}{l}\text { Physical } \\
\text { locus } c\end{array}$ & $\begin{array}{l}\text { Genetic } \\
\text { locus } w\end{array}$ \\
\hline $41 \mathrm{~F} 11$ & 837 & $55 \cdot 1$ \\
\hline $42 \mathrm{~F} 3$ & 887 & $55 \cdot 9$ \\
\hline 43F9 & 935 & $57 \cdot 2$ \\
\hline $44 \mathrm{~F} 12$ & 982 & $58 \cdot 8$ \\
\hline $45 \mathrm{~F} 8$ & 1035 & $60 \cdot 7$ \\
\hline $46 \mathrm{~F} 11$ & 1094 & $62 \cdot 6$ \\
\hline $47 \mathrm{~F} 18$ & 1163 & $64 \cdot 5$ \\
\hline $48 \mathrm{~F} 11$ & 1215 & $65 \cdot 9$ \\
\hline $49 \mathrm{~F} 15$ & 1273 & $67 \cdot 4$ \\
\hline 50F9 & 1345 & $69 \cdot 5$ \\
\hline $51 \mathrm{~F} 13$ & 1407 & $71 \cdot 9$ \\
\hline $52 \mathrm{~F} 11$ & 1472 & $75 \cdot 1$ \\
\hline $53 \mathrm{~F} 13$ & 1537 & $79 \cdot 0$ \\
\hline $54 \mathrm{~F} 6$ & 1592 & $82 \cdot 8$ \\
\hline $55 \mathrm{~F} 13$ & 1650 & $87 \cdot 5$ \\
\hline $56 \mathrm{~F} 17$ & 1709 & 92.5 \\
\hline $57 \mathrm{~F} 11$ & 1782 & $98 \cdot 9$ \\
\hline $58 \mathrm{~F} 8$ & 1829 & $102 \cdot 8$ \\
\hline $59 \mathrm{~F} 8$ & 1869 & 105.5 \\
\hline $60 F 5$ & 1939 & $108 \cdot 1$ \\
\hline
\end{tabular}

Chromosome 4

$\begin{array}{ccc}\text { Physical } & \text { Physical } \\ \text { Band } & \text { locus } c & \text { locus } w \\ 101 F 7 & 42 & 0 \cdot 2 \\ 102 \text { F17 } & 137 & 3 \cdot 1\end{array}$

even in chromosomal regions that are sparsely mapped. Discrepancies must be partly due to errors in map assignments: for example, it would be surprising if $r$ st and $\mathcal{N}$ lying only 3 bands apart have a map distance of $1.3 \mathrm{cmo}$ as reported.

Clearly chiasmata are not distributed uniformly along the physical map. The hypothesis that density of structural loci is inversely proportional to 
chiasma frequency is contradicted by the genetic map, where loci cluster in regions of low crossing-over. Therefore a uniform distribution of loci on the genetic map is only a crude approximation, and should not be incorporated into linkage analysis as some Bayesians do (Renwick, 1971).

A double beta distribution of chiasmata gives a reasonable fit to the genetic map and may be useful to estimate genetic and physical locations. While mixtures of more than two distributions may improve the accuracy of the map, a double distribution gives an adequate fit and avoids convergence problems involved in estimating many parameters (e.g. 8 for a triple distribution). If the chiasma distribution were observed instead of deduced, it would be feasible to distinguish arms with one chiasma from those with more, making the double distribution still more acceptable (Morton et al., 1976).

TABle 4

Correspondence between physical and genetic locations

$\begin{array}{ccccccr}\text { Marker } & \begin{array}{c}\text { Chromosome } \\ \text { arm }\end{array} & \begin{array}{c}\text { Physical } \\ \text { location }\end{array} & \begin{array}{c}\text { Band } \\ y\end{array} & \begin{array}{c}\text { Assigned } \\ \text { genetic } \\ \text { location } w y\end{array} & \begin{array}{c}\text { Estimated } \\ \text { genetic } \\ \text { location }\end{array} & \begin{array}{c}\text { Estimated } \\ \text { band }\end{array} \\ z & \mathbf{X} & 3 \mathrm{~A} 3 & 90 & 1 \cdot 0 & 2 \cdot 2 & 57 \\ r s t & \mathbf{X} & 3 \mathrm{C} 4 & 105 & 1 \cdot 7 & 3 \cdot 7 & 80 \\ \mathcal{N} & \mathbf{X} & 3 \mathrm{C} 7 & 108 & 3 \cdot 0 & 4 \cdot 0 & 98 \\ B & \mathbf{X} & 16 \mathrm{~A} 1-2 & 820 & 57 \cdot 0 & 56 \cdot 8 & 823 \\ e x & \text { 2L } & 21 \mathrm{C} 3 & 15 & 0 \cdot 1 & 1 \cdot 0 & 2 \\ L y & \text { 3L } & 70 \mathrm{~A} 3-5 & 476 & 40 \cdot 5 & 38 \cdot 2 & 514 \\ s s & \text { 3R } & \text { 39C1-2 } & 1376 & 58 \cdot 5 & 58 \cdot 6 & 1375\end{array}$

The classical Drosophila geneticists used crude empirical mapping functions, but they had a clear conception of what they were doing: "The serial order of the loci is the most important information represented by the map. .. . The distances between loci are also represented, but this type of information is by no means so unquestionable as is the serial order. The serial order can be established absolutely, except in those cases where the loci of recessives are so close together that double recessives are too difficult to obtain. ... As new data accumulate it becomes advisable occasionally to discard the old map completely, as far as distances are concerned, and to calculate a new map, considering all the data simultaneously" (Bridges and Morgan, 1923).

Unfortunately two circumstances have made Drosophila geneticists honour this counsel in the breach. First, the linkage map soon came to include hundreds of loci, and the three-point backcrosses which alone could establish the order of closely linked genes became prohibitively tedious. Secondly, as the theoretical interest of extending the linkage map decreased, data were no longer published in detail. Consequently the old linkage map has been extended but not corrected. For example, the distance between $r u$ and $s e$ is still taken as $26.0 \mathrm{cmo}$ (Lindsley and Grell, 1968) just as it was estimated by Bridges and Morgan without correction for multiple crossingover, and the intervening loci have been forced into an interval that is presumably underestimated. This may create spurious irregularities in the chiasma map. Perhaps such systematic errors are negligible relative to biases due to differential viability and variations in map distance with maternal age and genotype. However, it may be hoped that the linkage map 
of man will be developed according to the precept of Bridges and Morgan, so that data collected laboriously and expensively will be accessible for subsequent reanalysis. The mooted convention of publishing lod scores for recombination values of 0.1 and 0.3 only (McKusick and Edwards, 1975) is hardly adequate for that purpose.

After the manuscript of the present paper was submitted for publication we learned through correspondence with Professor Lindsley of a paper by Lindsley and Sandler (in press). Their plots of loci on the chiasma map agree substantially with our continuous distributions, including the peak of recombination in DNA-rich bands near the white locus on the X chromosome. Even when expressed relative to DNA content, the chiasma distribution is markedly reduced near the telomeres and centromeres.

\section{REFERENCES}

ABramowitz, M., AND STEgun, I. A. (Ed.). 1965. Handbook of Mathematical Functions. Dover Publications, New York.

BRIDGes, C. B., AND MORGAN, T. H. 1923. The Third-Chromosome Group of Mutant Characters of Drosophila melanogaster. Carnegie Institution of Washington, Washington.

BRIDGES, P. N. 1942. A new map of the salivary gland 2L-chromosome of Drosophila melanogaster. F. Heredity, 11, 403-408.

LINDSLEY, D. L., AND GRELl, E. H. 1968. Genetic Variations of Drosophila melanogaster. Garnegie Institute of Washington, Publication No. 627.

LINDSley, D. L., AND SANDler, L. 1976. The genetic analysis of meiosis in female Drosophila melanogaster. Proc. Roy. Soc. (Lond.) Ser. B (in press).

MATHER, K. 1936. The determination of position of crossing-over. I. J. Genet., 33, 207257.

MCKUSICK, v. A., AND EDWARDS, J. H. 1975. Unassigned systenic groups and theoretical considerations. In Human Gene Mapping 2, Rotterdam Conference (1974). Birth Defects: Original Article Series XI, No. 3, ed. D. Bergsma, pp. 26-28. Karger, Basel.

MORTON, N. E., RAO, D. C., LiNDSTEN, J., AND yeE, S. 1976. A chiasma map of man. Human Heredity (in press).

ReNwICK, J. H. 1971. The mapping of human chromosomes. Ann. Rev. Genet., 5, 81-120. 